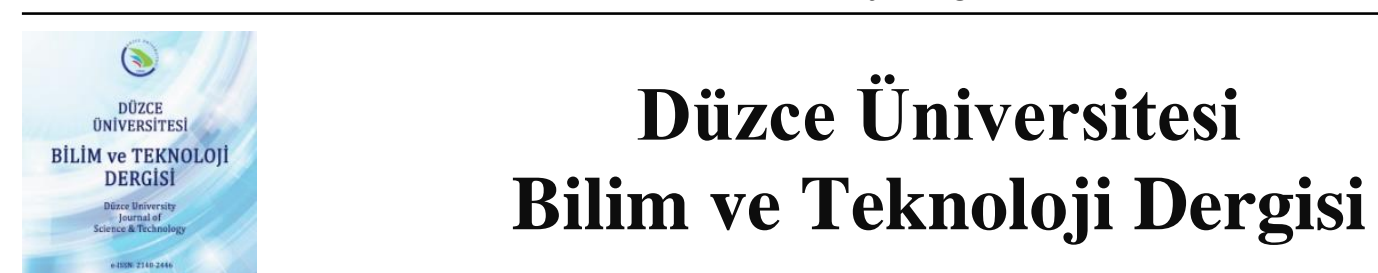

Araştırma Makalesi

\title{
İnsansız Hava Aracı ile Görüntü İşleme ve Yapay Zekâ Teknikleri Kullanılarak Yangın Tespiti: Örnek Bir Uygulama ${ }^{1}$
}

(iD) Bekir AKSOY ${ }^{\mathrm{a}, *}$, (D) Kaan KORUCU ${ }^{\mathrm{a}}$, (D) Önder ÇALIŞKAN ${ }^{\mathrm{a}}$, (D) Şaban OSMANBEY ${ }^{\mathrm{a}}$, (D) Helin
Diyar HALIS $^{\mathrm{a}}$

${ }^{a}$ Isparta Uygulamalı Bilimler Üniversitesi Teknoloji Fakültesi Mekatronik Mühendisliği Bölümü

* Sorumlu yazarın e-posta adresi: bekiraksoy@isparta.edu.tr

DOI: 10.29130/dubited.1016195

\begin{abstract}
ÖZ
Son yıllarda orman ve şehir yangınlarının artması tüm dünya için önemli bir sorun oluşturmaktadır. Ekolojik ve ekonomik açıdan büyük kayıplara sebep olan yangınlar, karbon döngüsünü bozarak orman dinamiklerine de ciddi zarar vermektedir. Bu doğrultuda yaşamın gerekliliği açısından önemli ekosistemlerden olan ormanların ve doğanın korunması önem arz etmektedir. Orman ve șehir yangınları ile mücadelede yangının erken tespiti büyük kayıpların önüne geçmektedir. Teknolojinin gelişimi ile birlikte yangınların erken tespit edilebilmesi amacıyla insansız hava araçları (IHHA), yapay zekâ ve görüntü işleme tekniklerinden yararlanılmaktadır. Çalışmada, yangının erken tespiti üzerinde duruldu ve yangının erken tespit edilebilmesi için insansız hava aracı tasarlandı. Çalışmada, görüntü işleme ve yapay zekâ tekniklerinden yararlanılarak görüntülerde ateş tespiti yapılmakta ve akabinde yangın tespit edilen konum belirlenmektedir. Çalışmada sonuç olarak kullanılan mimarinin karmaşıklık matrisine göre performansı değerlendirilerek, \%96 doğruluk, \%98 duyarlılık, \%89 özgüllük ve \%96 kesinlik değerleri bulunmuştur. Gerçekleştirilen çalışma sayesinde yangının erken tespiti sağlanacak ve hızlı müdahale gerçekleştirilecektir.
\end{abstract}

Anahtar Kelimeler: Insansız hava aracı, Yangın tespiti, Görüntü işleme, Yapay Zekâ

\section{Fire Detection Using Unmanned Aerial Vehicle Imaging Processing and Artificial Intelligence Techniques: A Sample Application}

\begin{abstract}
The increase in forest and city fires in recent years is an important problem for the whole world. Fires, which cause great ecological and economic losses, also cause serious damage to forest dynamics by disrupting the carbon cycle. In this direction, it is important to protect forests and nature, which are important ecosystems in terms of the necessity of life. In the fight against forest and city fires, early detection of fire prevents great losses. With the development of technology, unmanned aerial vehicles (UAV), artificial intelligence and image processing techniques are used in order to detect fires early. The study focused on the early detection of the fire and an unmanned aerial vehicle was designed to detect the fire early. In the study, fire detection is made in the images by using image processing and artificial intelligence techniques, and then the location where the fire is detected is determined. As a result, the performance of the architecture used in the study was evaluated according to the complexity matrix, and the values of $96 \%$ accuracy, $98 \%$ sensitivity, $89 \%$ specificity and $96 \%$ precision were found. Thanks to the work carried out, early detection of the fire will be ensured and rapid intervention will be carried out.
\end{abstract}

Keywords: Unmanned aerial vehicle, Fire detection, Image processing, Artificial intelligence

${ }^{1}$ ICAIAME 2021 konferansında sunulmuş olup, özet metin olarak basılmıştır. 


\section{GIRIS}

Ormanlar, yaşamın sürekliliği açısından önemli ekosistemlerdir. Geçtiğimiz yıllarda, doğal ya da insani sebepler ile yaşanan iklim değişikliği ve orman kayıpları, biyolojik çeşitlilik krizi ve ekosistem hizmetlerinin sağlamaması üzerine endişe oluşturmaktadır [1]. Orman yangınları, karbon döngüsünü bozarak orman dinamiklerine zarar vermektedir. Orman yangınları sonucu azalan orman alanları ise küresel ısınmanın ana nedenlerinden birisidir [2]. Ekolojik ve ekonomik açıdan büyük kayıplara sebep olan orman ve şehir yangınlarını en aza indirmek için yangınların sebeplerini anlamak ve takiben önlem almak gerekmektedir [3]. Yangının başladığı noktada ise, yangın belirli bir noktada başlayıp daha fazla alana yayılma eğiliminde olduğundan erken tespit edilerek müdahale edilmesi önem arz etmektedir. Gelişen teknoloji ile birlikte, orman veya şehir yangınlarının erken tespit edilebilmesi için insansız hava araçları kullanılmaktadır.

Günümüzde insansız hava araçlarının kullanımı askeri alanda olduğu kadar günlük hayatta da artmıştır. İnsansız hava araçları, esnek kullanım alanı, hızlı ve yüksek manevra kabiliyeti, uydu görüntülerine göre küçük alanların izlenmesinde daha iyi çözünürlük sağlaması gibi avantajlara sahiptir. İnsansız hava araçları, fotoğrafçılık, tarım, gözetleme, taşımacılık gibi farklı birçok alanda kullanıldığı gibi yangın takip ve söndürme amacıyla da kullanılmaktadır. İnsansız hava araçlarının kullanım alanlarının genişlemesiyle birlikte ulaşılabilirliği artmıştır [4]. İnsansız hava araçlarının kullanımının artmasıyla insansız hava aracı ile entegre olarak görüntü işleme ve yapay zekâ uygulamaları sıklıkla kullanılmaktadır.

Yapay zekâ, bilgisayarların insan zekâsının öğrenme ve akıl yürütme gibi becerilerini modellemesine izin veren yazılımsal ve donanımsal sistemler bütünüdür. Yapay zekâ, karmaşık olan verileri çeşitli yöntemler ile analiz ederek daha anlaşılabilir olması için yorumlayan ve kazandığ 1 tecrübeler doğrultusunda kendini geliştiren sistemlerdir [5]. Görüntü işleme, görüntüyü dijital forma dönüştürerek ve akabinde işleyerek görüntü üzerinden yararlı bilgileri çıkartmak için kullanılan bir yöntemdir [6]. Görüntü işlemede, elektronik ortama aktarılan görüntü, görüntü ön işleme aşamasından geçmektedir. Görüntü ön işleme, performansı ve kaliteyi doğrudan etkilemektedir [7]. Görüntü ön işleme aşamasında parazit ve gürültü oranı azaltılarak görüntüyü iyileştirmeye yönelik farklı birçok teknik uygulanmaktadır [8]. Görüntü ön işleme aşamasında sıklıkla kullanılan tekniklerden biri filtreleme yöntemleridir. Filtreleme yöntemleri ile görüntüye verilen farklı efektler sayesinde fiziksel özellikler arasındaki ayrımın belirginleşmesi sağlanarak veya minimum düzeye getirilerek görüntü daha kolay yorumlanabilmektedir [9].

Görüntü işleme, medikal görüntülerin incelenmesi [10], bitki hastalıklarının tespiti [11], plaka tanıma sistemi [12] gibi farklı birçok alanda kullanılmaktadır. Görüntü işlemenin kullanıldığı önemli alanlardan birisi de insansız hava araçlarıyla entegre olarak yangın tespitidir. İnsansız hava aracı ile görüntü işleme ve yapay zekânın yangın tespiti üzerine kullanıldığı akademik çalışmalar incelendiğinde;

Yuan ve ark. [13] çalışmalarında, insansız hava aracı ile yangın tespit ve takibi üzerine görüntü işleme tekniklerini kullanmışlardır. İnsansız hava aracıyla iletilen görüntülerden yangının tespit edilebilmesi yangının renk hareket ve geometrisi ile sağlanmaktadır. Çalışmalarında görüntü işleme aşamaları olarak, medyan filtreleme, renk modeli dönüştürme, görüntü bölütleme ve morfolojik işlemlerden yararlanmışlardır. Görüntüdeki renk bilgisi yangının tespitinde ön işleme adımı olarak kullanılmaktadır. Gerçekleştirilen çalışmada farklı renk kanallarında örnek görüntüler incelenmiş sonuç olarak Lab renk modeli "a" kanalının daha iyi performans ortaya koyduğu ve deneysel sonuçlar ile önerilen yöntemin yangın piksellerini etkin bir şekilde çıkarabildiğini göstermişlerdir.

Yuan ve ark. [14] çalışmalarında, orman yangınının erken tespiti ve yangına hızlı müdahale edilmesi amacıyla görüntü işleme tabanlı insansız hava aracı kullanmışlardır. Çalışmalarında yangının renk ve hareket özelliklerine göre birlikte tespiti sağlanmıştır. Çalışmada yangının algılanması, Lucas-Kanade (LK) optik akış algoritması ve renk bazlı yangın algılama ile gerçekleştirilmiştir. LK, parlaklık tutarlılığı varsayımı ile renk tabanlı algılama ise ateş renginin kırmızı ve sarı arasındaki renk değer aralığı olduğu 
benimsenerek gerçekleşmektedir. Çalışmalarında sonuç olarak, optik akış yöntemi ve renk tabanlı algılama ile hareket ve renk öznitelikleri çıkartılmış ve geliştirdikleri yöntemin etkinliği kapalı bir ortamda test edilerek kanıtlanmıştır.

Sudhakar ve ark. [15] orman yangınlarındaki yanlış alarmları azaltmak için insansız hava aracı ile orman yangınını algılama üzerine çalışma gerçekleştirmişlerdir. Çalışmalarında yangının algılanmasında hareket eden nesnelerin sebep olduğu yanlış alarmları azaltmak için optik akış sensöründen yararlanmışlardır. Renk tabanlı algılama ile görsellerdeki potansiyel yangın alanı belirlenmekte ve doğrulama için harekete dayalı algoritma kullanmışlardır. Yangının renk ve hareket bilgilerini birleştirerek yangının kesinliği sağlanmaktadır.

Lee ve ark. [16] çalışmalarında, orman yangının tespit edilebilmesi amacıyla evrişimli sinir ağları ile insansız hava aracını entegre olarak kullanmışlardır. Çalışmalarında, havadan alınan yüksek çözünürlüklü görüntüler ile orman yangınını algılayabilen bir sistem geliştirmişlerdir. Geliştirdikleri sistemde yangın olan 10985, yangın dışı 12068 görüntü kullanmışlardır. Çalışmalarında, AlexNet, GoogLeNet, VGG13, modifiye edilmiş GoogLeNet ve modifiye edilmiş VGG13 evrişimli sinir ağları değerlendirilerek, GoogLeNet ile \%99 doğruluk oranıyla en yüksek doğruluk elde edildiği ortaya koyulmuştur.

Çalışma üç aşamadan oluşmaktadır. İlk aşamada yangınlar, insansız hava aracı, yapay zekâ ve görüntü işlemeden kısaca bahsedilerek, yangın tespiti üzerine gerçekleştirilen ilgili çalışmalar incelenmiştir. İkinci aşamada ise tasarlanan insansız hava aracında kullanılan temel malzemeler ve yararlanılan görüntü işleme ve yapay zekâ yöntemleri açıklanmıştır. Üçüncü aşamada ise kullanılan modelin test veri setindeki doğruluk, duyarlılık, özgüllük ve kesinlik performans değerlendirme ölçütleri tablo halinde verilmiştir. Çalışmanın sonuç bölümünde, insansız hava aracı ile görüntü işleme ve SqueezeNet mimarisinin yangın tespitinde kullanılmasının performans sonuçları verilmiştir. SqueezeNet mimarisinin insansız hava aracı ile yangın tespitinde \%96,482 doğruluk değeri ile başarılı bir sonuç verdiği tespit edilmiştir.

\section{MATERYAL VE METOT}

\section{A. MATERYAL}

Çalışmada, veri bilimciler ve makine öğrenimi uygulayıcı topluluğu olan açık erişim internet sitesi Kaggle'dan [17] alınan veri seti kullanılmıştır. Veri seti, 755 yangın içeren, 244 yangın içermeyen görüntüden oluşmaktadır. İHA ile yangın tespiti yapabilmek için Python programlama dili kullanılarak, yapay zekâ ve görüntü işleme tekniklerinden yararlanılmıştır. Yangın tespitinde kullanılan teknikler aşağıdaki başlıklarda incelenmiştir.

\section{A.1. İnsansız Hava Aracı Tasarımında Kullanılan Temel Parçalar}

Çalışmada iki motorun saat yönünde, iki motorun saat yönünün tersine hareket ettiği, dört kolu olan ve her birinin motor ve pervaneye bağlı olduğu dört rotorlu İHA tasarlanmıştır. Çalışmada kullanılan İHA'nın tasarımı için gerekli olan temel donanım aşağıda verilmiştir.

\section{A.1.1. Gövde}

İHA tasarımında ilk olarak gövdeden başlamak gerekmektedir. Gövde, tüm parçaların tutturulduğu bir çerçevedir. İHA'lar taşıyacakları ağırlığa göre ince ayarda çalıştıkları için ve manevra kabiliyetini arttırmak amacıyla çerçeveleri genellikle hafif kompozit malzemelerden yapılmaktadır. Quadcopterler, x gövde, h gövde ve kolların 60 derece olduğu hibrit x gövde olmak üzere üç farklı gövde yapısına sahiptir. İhtiyaç duyulan büyüklüğe ve kullanılacak alana göre gövde yapısı seçilmektedir. Çalışmada 
gövde olarak F450 Quadcopter Drone Frame kullanılmıştır. Kullanılan gövdenin özellikleri aşağıda verilmiştir;

- $\quad$ Çerçevenin iki kırmızı, iki beyaz olmak üzere dört kolu bulunmaktadır.

- $\quad$ Çerçeve ağırlığı $282 \mathrm{~g}$, motordan motora çapraz uzunluk $450 \mathrm{~mm}$, kalkış ağırlığı $800 \mathrm{~g}-1600 \mathrm{~g}$

dir.

- $\quad$ ESC'lerin gövdeye lehimlenmesi için PCB şasesi bulunmaktadır.

- $\quad$ Uçuş kontrol sistemi için büyük bir montaj alanı sağlamaktadır.

\section{A.1.2. Motor}

Motorlar İHA'nın güç sistemine hakim olan ve pervaneleri döndürmeyi sağlayan parçalardır. İHA'da her kol için bir adet motor ve pervane kullanılmıştır. Motor seçimi İHA'nın ağırlığına göre seçilmektedir. Genellikle firçasız motor seçilmektedir. Fırçasız motorlar diğer motorlara kıyasla daha yüksek verim ile daha güçlü, daha hızlı çalışmakta ve daha uzun süre çalışma avantajlarına sahiptir [18]. Çalışmada EMAX XA2212 1400KV firçasız DC motor kullanılmıştır. Kullanılan motor, birden fazla rotor ve pervane ile çalışan IHA'lar için özel olarak tasarlanmıştır. Motorun kurulumu kolay olup çalışma sırasında daha az ısı üretmektedir. Kullanılan motorun teknik özellikleri aşağıda verilmiştir;

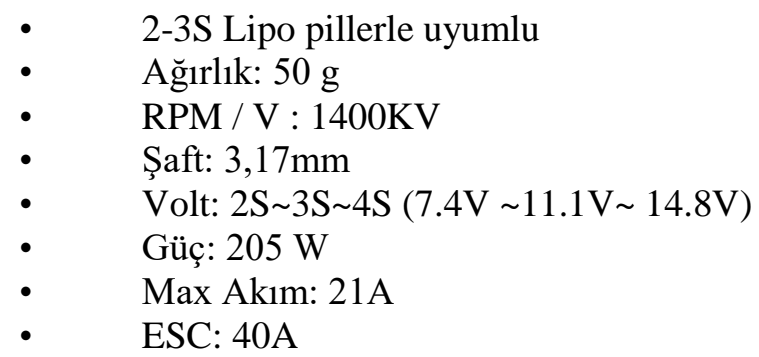

\section{A.1.3. Uçuş Kontrol Kartı}

İHA'nın hareketi esnasındaki rüzgâr etkisi gibi öngörülmeyen zorluklar veya motorun, pervanelerin arasındaki farklılıklar ile gövdenin her bir ucu farklı itiş kuvvetlerine maruz kalabilmektedir. Uçuşun güvenli ve verimli olması için güvenilir oto pilot sistemlere sahip olması gerekmektedir [19]. Uçuş kontrolörü, sistemin beyni olarak nitelendirilen, kullanıcın isteklerine göre İHA'nın kontrolünü sağlama, dengede kalma, batarya kontrolü gibi işlemleri gerçekleştiren birimdir. Uçuş kontrol kartı sensörlerden aldığ sağlamaktadır. Uçuş kontrol kartlarında, jiroskop, ivme ölçer, barometre en çok kullanılan sensörler arasındadır. Kullanılan sensörler İHA'nın stabilizasyonu sağlamaktadır. Çalışmada uçuş kontrol kartı, Ardupilot APM 2.8 kullanılmıştır. Ardupilot APM 2.8'in teknik özellikleri aşağıda verilmiştir;

- $\quad$ Arduino ile uyumlu

- $\quad$ Barometre, jiroskop, ivmeölçer ve manyetometre içermekte

- $\quad$ GPS modülü ile kullanılabilir

- $\quad$ Boyut: $44 \times 70 \times 15 \mathrm{~mm}$

- $\quad$ Ağırlık: $29 \mathrm{~g}$

\section{A.1.4. Elektronik Hoz Kontrolü}

Elektronik hız kontrolü (ing. Electronic Speed Control, ESC), İHA'da firçasız DC motorun çalıştırılması için gerekli olan, motorun hızını, rotasını kontrol eden bir elektronik devredir. ESC, uçuş kontrolünden aldığı sinyal doğrultusunda motorun hızını ve yönünü değiş̧tirmektedir [20]. Her motor için bir adet ESC bulunmakta ve bir ucu motora diğer ucu uçuş kontrol kartına bağlanmaktadır. ESC'ler motorun performansı için önemli olduğundan dolayı seçimine dikkat etmek gerekmektedir. ESC'nin motora çekebileceği maksimum akımı verebilmesi için seçiminde akım değerine dikkat edilmeli ve daha yüksek 
akım verebilen ECS seçilmektedir. Çalışmada kullanılan 30A firçasız ESC opto teknik özellikleri aşağıdaki verilmiştir;

- $\quad$ Maksimum akım kapasitesi: 30A (Anlık 45A 10sn)

- $\quad$ Giriş voltaj aralığı: 7.4V-22V (2S-6S)

- $\quad$ Ölçüler: $30 \mathrm{~A}-45$ x 24 x 8mm

- $\quad$ Ağırlık: $23 \mathrm{~g}$

\section{A.1.5. Kumanda Sistemi}

İHA'yı doğru ve kontrollü uçurabilmek için gerekli olan kumanda sistemi alıcı ve verici modüllerden oluşmaktadır. Doğru uçuşun gerçekleştirilmesi için kumanda en az dört kanallı seçilmelidir. Kumanda, İHA üzerindeki alıcı ile uyumlu radyo frekansında seçilmelidir. Verici modül yer istasyonunda bulunmakta ve verilen komutları radyo sinyaline çevirmektedir. Verici modül ile aynı radyo frekansında olan alıcı modül aldığı sinyali elektriksel güce çevirmektedir. Çalışmada kullanılan kumanda sistemi, $2.4 \mathrm{GHz}$, altı kanal desteğine sahip bir kumandadır. Tablo 1'de FlySky FS-CT6B kumanda vericisinin ve alıcısının teknik özellikleri verilmiştir.

Tablo 1. Kumanda seti teknik özellikler

\begin{tabular}{|c|c|}
\hline $\begin{array}{c}\text { Flysky FS-CT6B Kumanda } \\
\text { Vericisi }\end{array}$ & FS-R6BKumanda Alıcısı \\
\hline RF Aralığ1: 2.4055-2.475GHz & RF aralığı: $2.4055-2.475 \mathrm{GHz}$ \\
\hline RF kanal: 140 & RF kanal: 140 \\
\hline Bant Genişliği: $500 \mathrm{KHz}$ & Bant Genişliği: 500KHz \\
\hline 2.4GHz sistem: AFHDS & 2.4GHz Sistem: AFHDS 2A \\
\hline Modülasyon: GFSK & Modülasyon: GFSK \\
\hline Düşük Voltaj Aralığı: <9V & Çalışma voltaj1: 4.0-6.5V DC \\
\hline Anten uzunluğu: $26 \mathrm{~mm}$ & Anten uzunluğu: $26 \mathrm{~mm}$ \\
\hline Ağırlık: $511 \mathrm{~g}$ & Ağırlık: $13 \mathrm{~g}$ \\
\hline Ölçüler: 189 x 97 x 295 mm & Ölçüler: 52 x 35 x $15 \mathrm{~mm}$ \\
\hline
\end{tabular}

\section{A.1.6. Batarya}

İHA'larda kısa adı Li-Po olan lityum-polimer piller kullanılmaktadır. Bu piller, ağırlık ve boyutlarına oranla fazla enerji vermekte ve bitene kadar aynı akımı verdikleri için pil azaldığında da aynı performansı sürdürebilmektedir. Li-Po piller yüksek akım ve kapasiteye sahip tekrar şarj edilebilir bataryalardır. Li-Po pilin voltajı motorun özelliklerine göre ayarlanmaktadır. Li-Po pil $3.7 \mathrm{~V}$ gerilime sahiptir ve hücre sayıları arttıkça gerilim değeri 3.7'nin katı olarak artmaktadır. Genellikle tercih edilen 3 hücreli (3S) batarya, 3x3,7V dan 11,1V gerilime sahiptir. Li-Po pilin amperi seçilirken, kapasitelerini belirten " $\mathrm{C}$ " değerine dikkat edilmelidir. Li-Po pilin üzerindeki "C" değeri ile pilin amper değerinin çarpımı pilin sağladığı maksimum akım değeridir.

\section{A.1.7. Diğer Parçalar}

İHA'nın tasarımında kullanılan temel parçalar açıklanmıştır. Yangın tespitinde gerekli olan ve tasarıma eklenen yardımcı parçalar aşağıda maddeler halinde verilmiştir: 
Telemetri: Sistemin batarya durumu, hızı, yüksekliği, konumu gibi verileri aktaran, sistemin uzaktan izlenmesi ve kontrol edilmesini sağlayan birimdir. Çalışmada, DR-015 433MHZ 3DR radyo telemetri seti kullanılmıştır.

GPS Sensörü: İHA'nın kontrolünde kullanılan, dünya üzerindeki konumunu hesaplayan ve belli bir rotayı takip edebilmesini sağlayan sensördür. Çalışmada Ublox Neo-M8N GPS modülü kullanılmıştır.

Kamera: İHA'nın uçtuğu bölgeyi görmek, uçuş sırasında çekim yapabilmek için kullanılmıştır. Çalışmada, Mista 1000TVL Mini 2.8mm FPV kamera kullanılmıştır.

\section{A.2. Gaussian Filtreleme}

Gaussian görüntüleri etkili yumuşatma için kullanılan bir filtreleme yöntemidir [21]. Gauss filtresi, gürültüleri ve ayrıntıyı azaltmayı sağlamaktadır. Gauss filtesinde pikselin yoğunluk değeri, bulunduğu bölgedeki piksel değerlerinin ortalaması ile değişebilmektedir. Grubun içindeki piksel değeri en önemli etkiyi sağlarken, uzak değerler daha düşük bir rol oynamaktadır [22]. Gauss dağılımı Eşitlik 1'de iki boyutlu düzlem için, Eşitlik 2'de üç boyutlu uzay için gösterilmektedir.

$$
\begin{aligned}
& G(x)=\frac{1}{\sqrt{2 \pi \sigma}} e^{-\frac{x^{2}}{2 \sigma^{2}}} \\
& G(x, y)=\frac{1}{\sigma \sqrt{2 \pi}} e^{-\frac{x+y^{2}}{2 \sigma^{2}}}
\end{aligned}
$$

Formülde gösterilen $\sigma$ dağılımın standart sapmasıdır. Guassian filtrelemede iki boyutlu matematiksel ifade kullanılarak oluşturulan çekirdek matrisi görüntü üzerinde gezdirilmektedir. Gauss filtresi ne kadar geniş ise filtrenin kesme frekansı artmakta ve görüntü daha pürüzsüz olmaktadır. Gauss filtresi düşük frekanslara izin vermekte, daha yüksek frekansları engellemektedir. Keskin kenarlar piksel değeri değiştiğinden dolayı frekansı yüksek bölgelerden oluşmaktadır [23].

\section{A.3. Eşikleme}

Eşikleme, görüntü analizi uygulamalarında sıklıkla kullanılan, gri tonlamalı görüntü içindeki nesneleri arka plandan ayırmak için kullanılan bir yöntemdir [24]. Eşikleme yönteminde, görüntünün gri seviye dağılımlarını içeren histogramdan yararlanılmaktadır. Eşikleme tipine bağlı olarak pikseller belirli bir eşik değerine göre karşılaştırılmaktadır. Eşikleme yönteminin amacı, gri tonlamalı görüntüde ön planı arka plandan ayırmaktır. Piksel değerinin eşik değerinden yüksek olduğu durumda nesneye ait bir nokta olduğu, eşik değerinden düşük veya eşit olması durumunda bölge siyah kısım olarak kabul edilmekte ve arka plana ait bir nokta olduğu belirlenmektedir. İki seviyeli eşiklemenin matematiksel ifadesi Eşitlik 3 'de verilmiştir. Tanımlamada T eşik değeri olup, 1 ile etiketlenen piksellerin nesneye ait olduğu, 0 ile etiketlenen piksellerin arka plana ait olduğu gösterilmektir $[25,26]$.

$$
G(x, y)= \begin{cases}1 & f(x, y)>T \\ 0 & f(x, y) \leq T\end{cases}
$$

\section{A.4. SqueezeNet}

SqueezeNet2016 yılında Iandola ve ark. tarafından [27] sunulan, evrişimsel sinir ağları (CNN) içinde yer alan bir mimaridir. SqueezeNet evrişim ağ, 50 kat daha az parametre ile AlexNet'ten daha iyi performans göstermektedir. SqueezeNet mimarisi, beş farklı katmana sahip on beş katmandan oluşmaktadır [28]. SqueezeNet mimarisinde, daha verimli dağıtılmış katmanlar ile sinir ağındaki iş yükü azalmakta ve mimari daha hızlı çalışmaktadır. SqueezeNet mimarisiyle daha az parametre ile yüksek doğruluk elde edilmektedir [29]. 


\section{A.5. Performans Değerlendirme Ölçütleri}

Çalışmada modelin performansı karmaşıklık matrisi (confusion matrix) kullanılarak değerlendirilmiştir. Tablo 2'de karmaşıklık matrisi gösterilmektedir. Tablo 2'de gösterilen iki boyuta sahip karmaşıklık matrisi ile doğruluk (accuracy), duyarlılık (sensivity), özgüllük (specificity) ve kesinlik (precision) değerleri hesaplanmıştır.

Tablo 2. Karmaşıklık matrisi

\begin{tabular}{|c|c|c|c|c|}
\hline \multirow{3}{*}{$\begin{array}{c}\text { GERÇEK } \\
\text { DEGEER }\end{array}$} & \multicolumn{4}{|c|}{ TAHMİN EDİLEN DEĞER } \\
\hline & POZİTİF & $\begin{array}{l}\text { DOĞRU } \\
\text { POZITIIF } \\
\text { (True } \\
\text { positive- } \\
\text { TP) }\end{array}$ & $\begin{array}{c}\text { YANLIŞ } \\
\text { POZITIF } \\
\text { (Falsepositiv } \\
\text { e-FP) }\end{array}$ & POZİTİF \\
\hline & NEGATİF & $\begin{array}{l}\text { YANLIŞ } \\
\text { NEGATİF } \\
\text { (Falsenega } \\
\text { tive-FN) }\end{array}$ & $\begin{array}{c}\text { DOĞRU } \\
\text { NEGATIF } \\
\text { (True } \\
\text { negative- } \\
\text { TN) }\end{array}$ & NEGATİF \\
\hline
\end{tabular}

Doğruluk, modelin başarısını göstermekte ve Eşitlik 3'te verilen matematiksel ifade ile hesaplanmaktadır.

$D o \breve{g} r u l u k=\frac{T P+T N}{T P+T N+F P+F N}$

Duyarlılık, modelin yangın olan görselleri tahmin etmedeki olasılığı göstermekte ve Eşitlik 4'te verilen matematiksel ifade ile hesaplanmaktadır.

Duyarlllık $=\frac{T P}{T P+F N}$

Özgüllük, modelin yangın olmayan görüntüleri tahmin etmedeki olasılığını göstermekte ve Eşitlik 5'te verilen matematiksel ifade ile hesaplanmaktadır.

Özgüllü $k=\frac{T N}{T N+F P}$

Kesinlik, modelin yangın olarak tahmin edilen görsellerin kaç tanesinin pozitif olduğunu göstermekte ve Eşitlik 6'da verilen matematiksel ifade ile hesaplanmaktadır [30].

Kesinlik $=\frac{T P}{T P+F P}$

\section{B. METOT}

Gerçekleştirilen çalışmanın iş akış diyagramı Şekil 1'de verilmiştir. Çalışmada açık kaynaklı internet sitesi Kaggle'da yer alan veri setinden yararlanılarak modelin eğitim ve test işlemi gerçekleştirilmiştir. Veri seti, 755 yangın içeren, 244 yangın içermeyen görüntüden oluşmaktadır. Veri setindeki görüntüler $\% 80$ eğitim, \%20 test veri kümesi için ayrılmıştır. İlk aşamada görüntüler görüntü ön işleme aşamasından geçmektedir. Görüntüye sırasıyla gaussian filtreleme, eşikleme ve boyutlandırma işlemleri uygulanmıştır. Görüntü işleme yöntemleri uygulanan görüntüler SqueezeNet mimarisi ile eğitilmiştir. SqueezeNet mimarisi, daha küçük CNN mimarisi içermekte ve bu doğrultuda sağladığı avantajlar ile tercih edilmiştir. Modele ait hiper parametrelerin optimum değerleri belirlenmiştir. Öğrenme oranı optimize edilerek 0.005 olarak belirlenmiştir. Modelin epoch sayısı 10 olarak belirlenmiştir. Eğitim 
ardından modelin doğruluğu test edilmiştir. Modelin performansı karmaşıklık matrisi kullanılarak değerlendirilmiştir. Karmaşıklık matrisi ile modelin doğruluk, duyarlılık, özgüllük ve kesinlik değerleri hesaplanmıştır. İnsansız hava aracı ile görüntü aktarımı gerçekleştirilmiş ve sonrasında, görüntüde ateş algılandığında sistem "yangın var" olarak uyarı vermiştir. Yangın tespit edildiğinde GPS bilgisi ile yangının konumu belirlenmiştir. Belirlenen konum ve telemetri verileri bilgisayar ortamında anlamlı veriler halinde okunabilmesi adına string yazı tipine dönüştürülmüş ve bilgisayar ortamından konum, batarya gibi verilere ulaşılması sağlanmıştır. Böylelikle yangınların erken tespiti sayesinde daha büyük alanlara yayılmadan müdahale edilmesi daha hızlı bir şekilde gerçekleşecektir.

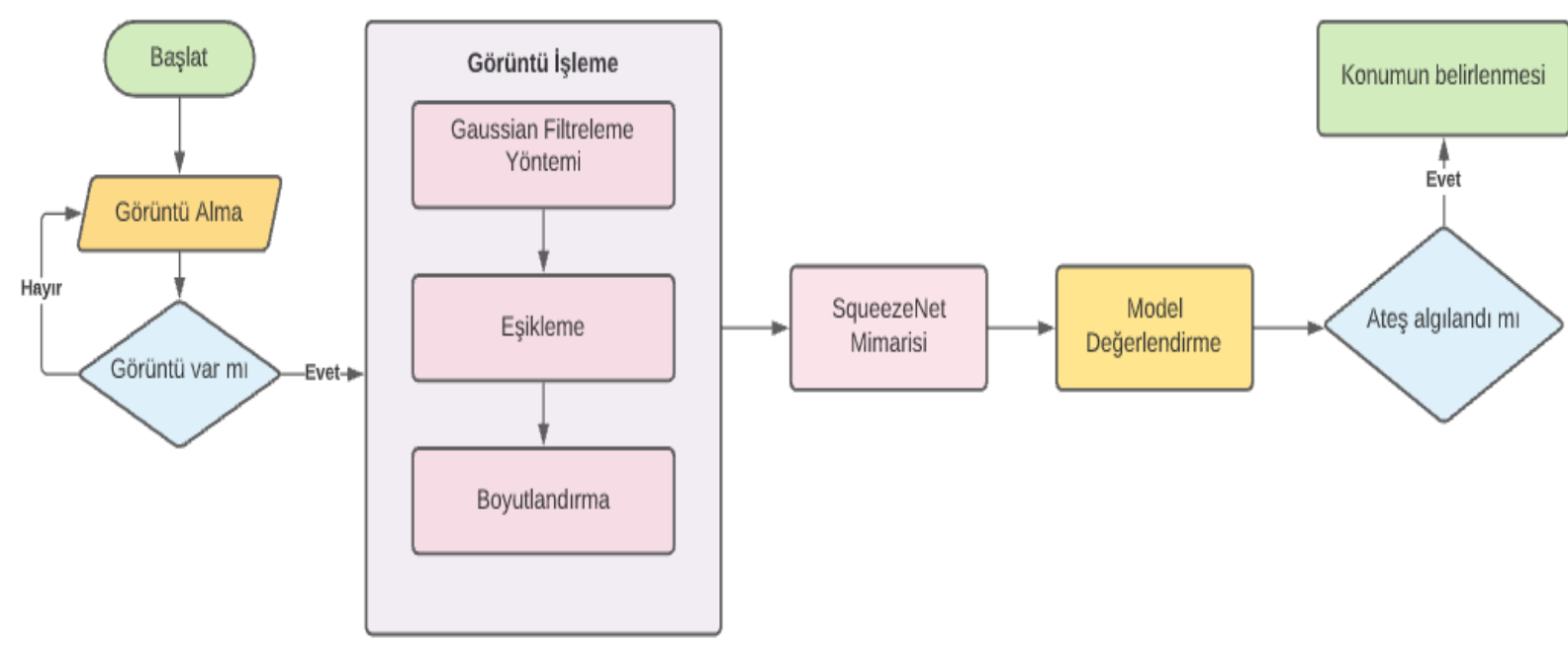

Şekil 1. İşaklş diyagramı

\section{ARASTIRMA BULGULARI}

Çalışmada, yangın tespiti yapmak üzere Python programlama dili kullanılarak yapay zekâ ve görüntü işlemeden yararlanılmıştır. Görüntüde ateşin tespit edilmesinde SqueezeNet modeli eğitim ve test için kullanılmıştır. Çalışmada görüntü işleme tekniklerinden; gaussian filtreleme, eşikleme ve boyutlandırma işlemleri kullanılmıştır. SqueezeNet modelinin test veri seti için karmaşıklık matrisi Şekil 2'de gösterilmiştir.

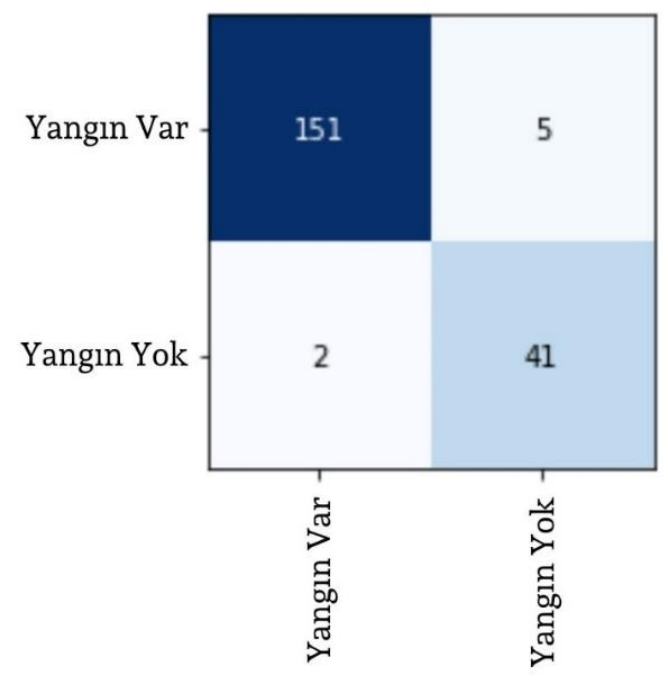

Şekil 2. SqueezeNet modeli karmaşıklık matrisi 
SqueezeNet modelinin performans değerlendirme sonuçları Tablo 3’te gösterilmiştir.

Tablo 3. SqueezeNet modeli performans değerlendirme sonuçlart

\begin{tabular}{cccc}
\hline Doğruluk & Duyarlılık & Özgüllük & Kesinlik \\
\hline 0,96482 & 0,98692 & 0,89130 & 0,96794 \\
\hline
\end{tabular}

Çalışmada modelin optimizasyonu sırasında önemli hiper parametre olan öğrenme oranı (ing.learning rate), eğitimin ilerleme oranını belirlemektedir. Öğrenme oranı, çalışmada optimum olarak 0.005 olarak belirlenmiştir. Öğrenme oranının büyük olması durumunda minimuma ulaşamaz, küçük olması durumunda ise model yavaş öğrenmektedir. Öğrenme oranı modelin test aşamasını önemli ölçüde etkilemektedir. Şekil 3’te görüldüğü gibi öğrenme oranının optimum değer aralığı kayıptaki en keskin düşüş ile ilişkilidir.

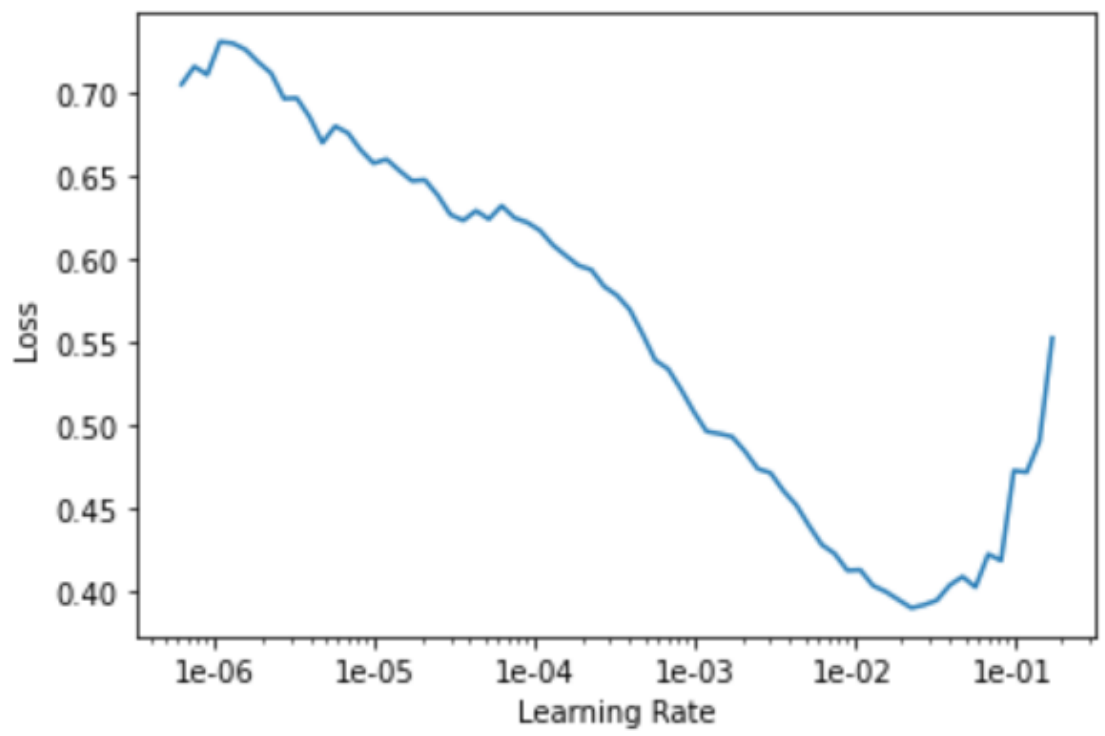

Şekil 3. Ö̆̆renme oranı dĕ̆ger aralı̆̆

\section{IV.SONUC}

Çalışmada, yangın tespitinde kullanılmak üzere insansız hava aracı tasarlanmıştır. Tasarlanan insansız hava aracı ile görüntü işleme teknikleri ve yapay zekâ entegre olarak yangının tespit edilmesinde kullanılmıştır. Görüntülerde ateşin tespit edilmesinde CNN içerisinde yer alan SqueezeNet mimarisi ile eğitim ve test işlemi gerçekleştirilmiştir. Model performans değerlendirme ölçütü olan karmaşıklık matrisine göre değerlendirilmiştir. Model dört farklı performans değerlendirme ölçütüne göre değerlendirilerek elde edilen sonuçlar doğrultusunda, \%96 doğruluk, \%98 duyarlılık, \%89 özgüllük ve \%96 kesinlik değerleri bulunmuştur. Çalışmada sonuç olarak, yapay zekâ ile yangın tespitinde SqueezeNet mimarisinin başarılı olduğu ve kullanılan görüntü işleme teknikleri gaussian filtreleme ve eşikleme yöntemlerinin yangın olup olmadığını algılamada etkin olduğu görülmüştür. İlerleyen çalışmalarda, farklı yapay zekâ mimarilerinin performansları kıyaslanarak, insansız hava aracı ile yangın tespitinde kıyaslanan farklı modeller arasında en başarılı modelin bulunması planlanmaktadır. Daha sonraki çalışmalarda, veri kümesi genişletilebilir, duman tespiti ile yangının erken tespiti sağlanabilir, duman tespiti için renk modelleri incelenebilir. Bu doğrultuda veri kümesi ve yapay zekâ mimarileri genişletilerek doğruluk oranı yükseltilebilir.

TEȘEKKÜR: Çalışmada kullanılan "FIRE-Dataset" açık kaynak verilerini internet sitesinde (Kaggle) kullanıma açan herkese teşekkürlerimizi sunarız. 


\section{KAYNAKLAR}

[1] J.E. Watson, T. Evans, O. Venter, B. Williams, A. Tulloch, C. Stewart, I. Thompson, J.C. Ray, K. Murray, A. Salazar, C. McAlpine, P. Potapov, J. Walston, J.G. Robinson, M. Painter, D. Wilkie, C. Filardi, W.F. Laurance, R.A. Houghton, S. Maxwell, H. Grantham, C. Samper, S. Wang, L. Laestadius, R.K. Runting, G.A. Silva-Chávez, J. Ervinand D. Lindenmayer, "The exceptional value of intact forest ecosystems," Nature Ecology\&Evolution, vol. 2, no. 4, pp. 599-610, 2018.

[2] V. Sevinc, O. Kucuk and M. Goltas, “A Bayesian network model forpredictionandanalysis of possible forest fire causes,"Forest Ecologyand Management, vol. 457, 2020.

[3] G. Zhang, M. Wang and K. Liu,"Forest fire susceptibilitymodelingusing a convolutionalneural network forYunnanprovince of China," International Journal of Disaster Risk Science, vol. 10, no. 3, pp. 386-403, 2019.

[4] D. Tezza and M. Andujar, "The state-of-the-art of human-drone interaction: A survey," IEEE Access, vol. 7, pp. 167438-167454, 2019.

[5] A. Hosny, C. Parmar, J. Quackenbush, L. H. Schwartz and H. J.Aerts, "Artificial intelligence in radiology," Nature Reviews Cancer, vol. 18, no. 8, pp. 500-510, 2018.

[6] S. R. Balaji and S. Karthikeyan, "A survey on moving object tracking using image processing,"IEEE 11th International Conference on Intelligent Systems and Control, 2017, pp. 469-474.

[7] X. Deng, Y.Ma and M. Dong, "A new adaptive filtering method for removing salt and peppernoise based on multilayered PCNN," Pattern Recognition Letters, vol. 79, pp. 8-17, 2016.

[8] A. Mohan and S. Poobal, "Crack detection using image processing: A critical review and analysis,"Alexandria Engineering Journal, vol. 57, no. 2, pp. 787-798, 2018.

[9] H. Michalak, and K. Okarma, "Improvement of imagebinarization methods using image preprocessing with localentropy filtering for alpha numerical character recognition purposes," Entropy,vol. 21, no. 6, 2019.

[10] O. Özkaraca, Y. Dere, G. Çetin ve M. Peker, "A computeraided system for calculation of Ki-67 proliferationindex," IEEE, In 2017 International Conference on ComputerScience and Engineering, 2017, pp. 580-585.

[11] S. D. Khirade and A.B. Patil, "Plant disease detection using image processing," IEEE, In 2015 International Conference on Computing Communication Control and Automation, 2015, pp. 768-771.

[12] O. Bingöl, ve Ö. Kuşcu, "Bilgisayar tabanlı araç plaka tanıma sistemi," Bilişim Teknolojileri Dergisi, c. 1, s. 3, 2008.

[13] C. Yuan, Z. Liu and Y. Zhang, "UAV-based forest fire detection and tracking using image processing techniques," IEEE, In 2015 International Conference on Unmanned Aircraft Systems, 2015, pp. 639-643.

[14] C. Yuan, K. A. Ghamry, Z. Liu and Y. Zhang,"Unmanned aerial vehicle based forest fire monitoring and detection using image processing technique,"In 2016 IEEE Chinese Guidance, Navigation and Control Conference, 2016, pp. 1870-1875. 
[15] S. Sudhakar, V. Vijayakumar, C.S. Kumar, V. Priya, L. Ravi and V. Subramaniyaswamy, "Unmanned Aerial Vehicle (UAV) based Forest Fire Detection and monitoring for reducing false alarms in forest-fires,"Computer Communications, vol. 149, pp. 1-16, 2020.

[16] W. Lee, S. Kim, Y.T. Lee, H.W. Lee and M. Choi, "Deep neural networks for wild fire detection with unmanned aerial vehicle,"In 2017 IEEE International Conference on Consumer Electronics, 2017, pp. 252-253.

[17] A. Said, (2021, Oct. 11), Fire-Dataset, [Online]. Available: https://www.kaggle.com/.

[18] X. Xu and Y. Deng, "UAV power component-DC brushless motor de-sign with merging adjacentdisturbances and integrated-dispatching pigeon-inspired optimization, "IEEE Transactions on Magnetics, vol. 54, no. 8, pp. 1-7, 2018.

[19] F. Santoso, M.A Garratt and S.G Anavatti, "State-of-the-art intelli-gent flight control systems in unmanned aerial vehicles," IEEE Transactions on Automation Science and Engineering, vol. 15, no. 2, pp. 613-627, 2017.

[20] X. Xue, "Optimization of Electronic Speed Controller (ESC) Power Quality," Ph.D. dissertation, Dept. Electrical Engineering, San Diego State University, USA, 2019.

[21] A. Kumar and S.S. Sodhi, "Comparative analysis of gaussian filter, median filter and denoise autoenocoder,"IEEE, 7th International Conference on Computing for Sustainable Global Development, 2020, pp. 45-51.

[22] Y. Li, M. Abdel-Monem, R. Gopalakrishnan, M. Berecibar, E. Nanini-Maury, N. Omar and J. Van Mierlo, "A quick on-line state of health estimation method for Liion battery with incremental capacity curves processed by Gaussian filter," Journal of Power Sources, vol. 373, pp. 40-53, 2018.

[23] W. Dong, S. Xiao and Y. Li, "Hyperspectral pansharpening based on guided filter and Gaussian filter," Journal of Visual Communication and Image Representation, vol. 53, pp. 171-179, 2018.

[24] T. Y. Goh, S. N. Basah, H. Yazid, M. J. A. Safar and F. S. A Saad, "Performance analysis of image thresholding: Otsu technique," Measurement, vol. 114, pp. 298-307, 2018.

[25] M. Abdel-Basset, V. Chang and R. Mohamed, "A novel equilibrium optimization algorithm for multi-thresholding image segmentation problems,"Neural Computing and Applications, vol. 33, no. 17, pp. 10685-10718, 2021.

[26] A. K. M. Khairuzzaman and S. Chaudhury, "Multilevel thresholding using grey wolf optimizer for image segmentation,” Expert Systems with Applications, vol. 86, pp. 64-76, 2017.

[27] F. N. Iandola, S. Han, M. W. Moskewicz, K. Ashraf, W. J. Dally and K. Keutzer, "SqueezeNet: AlexNet-level accuracy with 50x fewer parameters and< 0.5 MB model size," 2016, arXiv:1602.07360.

[28] F. Ucar and D. Korkmaz, "COVIDiagnosis-Net: Deep Bayes-SqueezeNet based diagnosis of the coronavirus disease 2019 (COVID-19) from X-ray images,” Medical Hypotheses, vol. 140, 2020.

[29] G. I. Sayed, M. M. Soliman and A. E. Hassanien, "A novel melanoma prediction model for imbalanced data using optimized SqueezeNet by bald eagle search optimization," Computers in Biology and Medicine, vol. 136, 2021, Art. no. 104712.

[30] A. Luque, A. Carrasco, A. Martín andA. Heras, "The impact of class imbalance in classification performance metrics based on the binary confusion matrix," Pattern Recognition, vol. 91, pp. 216-231, 2019. 